\title{
Publisher Correction: Structural insights into $\beta-1,3-$ glucan cleavage by a glycoside hydrolase family
}

Camila R. Santos (D), Pedro A. C. R. Costa, Plínio S. Vieira (D), Sinkler E. T. Gonzalez, Thamy L. R. Correa, Evandro A. Lima, Fernanda Mandelli, Renan A. S. Pirolla (D), Mariane N. Domingues, Lucelia Cabral, Marcele P. Martins, Rosa L. Cordeiro, Atílio T. Junior, Beatriz P. Souza, Érica T. Prates, Fabio C. Gozzo, Gabriela F. Persinoti ID, Munir S. Skaf and Mario T. Murakami iD

Correction to: Nature Chemical Biology https://doi.org/10.1038/s41589-020-0554-5, published online 25 May 2020

In the version of this article originally published, several lines and symbols were omitted from Fig. 1. The original and corrected Fig. 1 are shown in the correction notice. The error has been corrected in the HTML and PDF versions of the paper.
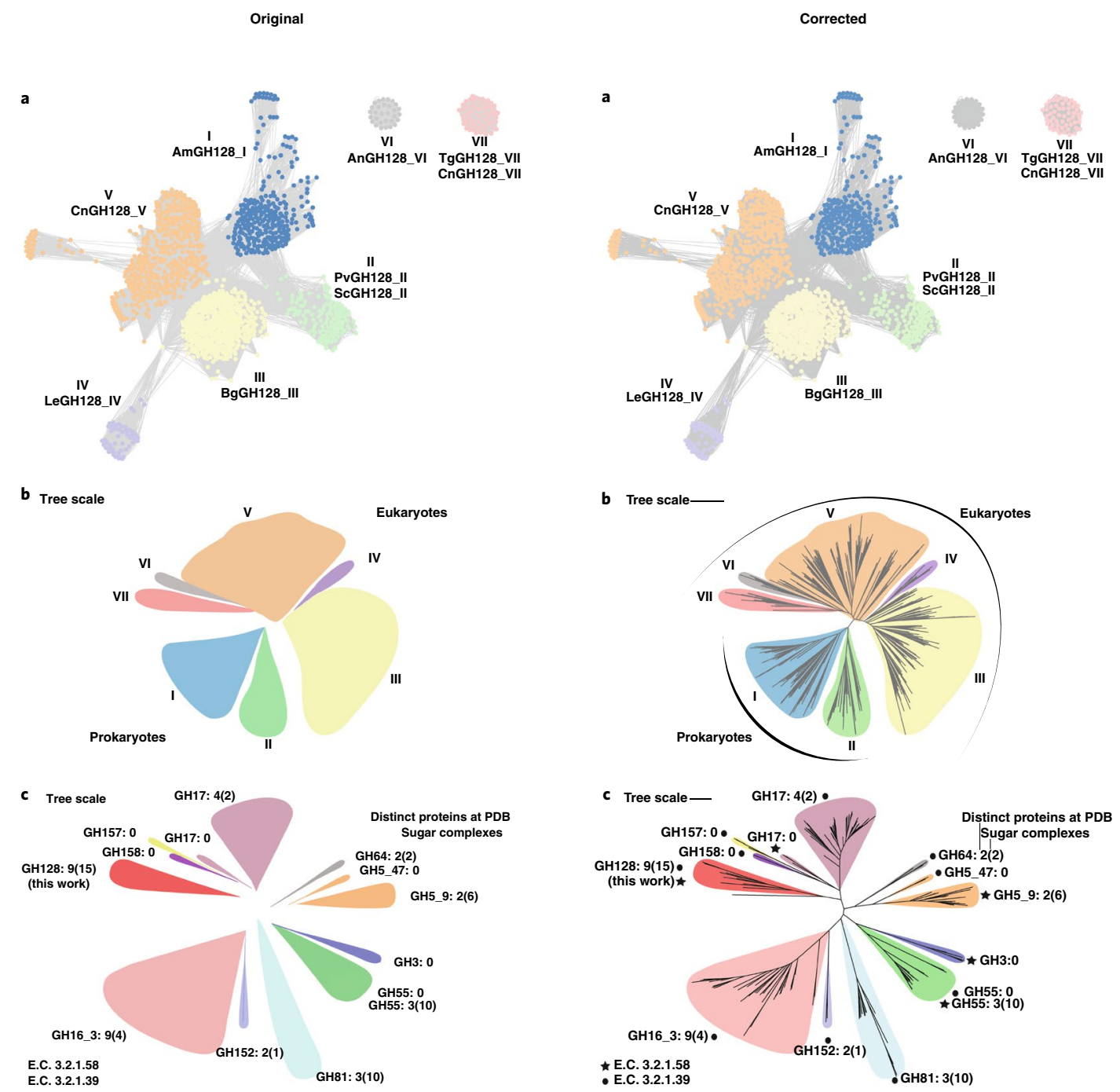

Fig. 1 | Clustering and phylogeny of the $\mathrm{GH} 128$ family.

Published online: 25 June 2020

https://doi.org/10.1038/s41589-020-0590-1

(c) The Author(s), under exclusive licence to Springer Nature America, Inc. 2020 